\title{
PROPRIEDADES FÍSICAS DE UM LATOSSOLO VERMELHO SOB CULTIVO DO ARROZ DE TERRAS ALTAS EM DIFERENTES MANEJOS DO SOLO E ÁGUA ( $\left.{ }^{1}\right)$
}

\author{
KARINA MARIE KAMIMURA $\left({ }^{2}\right)$; MARLENE CRISTINA ALVES $\left({ }^{3}\right)$; $\operatorname{ORIVALDO~ARF~}\left({ }^{4 *}\right)$; \\ FLÁVIO FERREIRA DA SILVA BINOTTI $\left({ }^{5}\right)$
}

\begin{abstract}
RESUMO
Na cultura do arroz, o manejo inadequado do solo pode ocasionar compactação superficial e subsuperficial que, ao limitar o desenvolvimento radicular e o armazenamento de água, compromete o crescimento e a produtividade das plantas. O trabalho teve como objetivo avaliar o efeito do manejo do solo e da água nas propriedades físicas de um Latossolo Vermelho Distrófico no cultivo do arroz de terras altas. O experimento foi instalado no município de Selvíria (MS), no ano agrícola de 2003/2004, em área anteriormente ocupada com a cultura do milheto. O delineamento experimental utilizado foi o de blocos casualizados em esquema fatorial $3 \times 3$, constituído de três manejos do solo (escarificador + grade niveladora, grade pesada + grade niveladora e semeadura direta) e três manejos da água (sem irrigação; irrigação nas fases reprodutiva e de maturação; irrigação em todas as fases), com quatro repetições. Analisaram-se macroporosidade, microporosidade, porosidade total, densidade do solo, resistência à penetração do solo, umidade do solo, condutividade hidráulica do solo saturado e infiltração de água. O preparo do solo com escarificador propiciou maior macroporosidade e porosidade total, e menor densidade do solo e resistência à penetração na camada de 0,00 a $0,20 \mathrm{~m}$, resultados opostos aos obtidos com o preparo com grade pesada; o preparo com grade proporcionou a formação de camada compactada $(0,10$ a $0,20 \mathrm{~m})$. A semeadura direta obteve menor macroporosidade e porosidade total, além de maior resistência à penetração e densidade do solo nos primeiros 0,10 $\mathrm{m}$. Pelos resultados, pode-se concluir que as propriedades físicas do solo foram influenciadas pelo seu manejo, entretanto não foram afetadas pelo manejo da água. O manejo do solo com escarificador resultou em melhores condições físicas para o desenvolvimento da cultura do arroz.
\end{abstract}

Palavras-chave: Oryza sativa L., escarificador, grade aradora, semeadura direta, irrigação por aspersão, compactação.

\section{ABSTRACT \\ PHYSICAL PROPERTIES OF AN OXISOL FOR A NON-FLOODED RICE CROP UNDER DIFFERENT SOIL AND WATER MANAGEMENTS}

For rice crops, the inadequate soil management can lead to superficial and sub-superficial compaction which, by limiting root development and water retention, limits crop growth and yield. This study was aimed at evaluating the soil and water management effect on the physical properties of an Oxisol under non-flooded rice. The experiment was carried out at Selvíria (MS), in the growing season of 2003/2004, in an area which had previously been under millet crop. A randomized complete block design was used in a $3 \times 3$ factorial scheme, based on three different soil managements (chisel plow + levelling harrow,

( $\left.{ }^{1}\right)$ Recebido para publicação em 27 de abril de 2006 e aceito em 11 de fevereiro de 2009.

$\left({ }^{2}\right)$ Aluna de Pós-graduação (Mestrado), Universidade Federal do Rio Grande do Sul, UFRGS. E-mail: karinamarie.kamimura@gmail.com.br

$\left({ }^{3}\right)$ Departamento de Fitossanidade, Engenharia Rural e Solos, Faculdade de Engenharia, UNESP - Campus de Ilha Solteira. E-mail: mcalves@agr.feis.unesp.br.

$\left({ }^{4}\right)$ Departamento de Fitotecnia, Tecnologia de Alimentos e Sócio-Economia, Faculdade de Engenharia, UNESP - Campus de Ilha Solteira. E-mail: arf@agr.feis.unesp.br $\left.{ }^{*}\right)$ Autor correspondente.

$\left.{ }^{5}\right)$ Aluno de Pós-graduação em Sistema de Produção (Doutorado), Faculdade de Engenharia, UNESP - Campus de Ilha Solteira, 15385-000 Ilha Solteira (SP). E-mail: flavio_agro@hotmail.com. 
harrow + levelling harrow and no-tillage) and three different water managements (not irrigated; irrigated during the reproductive and ripening stages; irrigated during all the stages), with 4 replications. Macroporosity, microporosity, total porosity, soil bulk density, soil penetration resistance, soil moisture content, hydraulic conductive of the saturated soil and water infiltration were analysed. Soil tillage with chisel plow produced greater macroporosity and total porosity, and lower soil bulk density and soil penetration resistance in the 0.00 to $0.20 \mathrm{~m}$ layer, opposite results obtained with harrow tillage. Harrow tillage formed a compacted layer at the depth of $(0.10-0.20 \mathrm{~m})$. Smaller macroporosity and total porosity was found in no-tillage together with greater soil penetration resistance and soil bulk density, all in the first $0.10 \mathrm{~m}$. Soil physical properties were influenced by soil management, but not influenced by water management. The soil management with chisel plow showed better results concerning the soil physical properties for the development of rice.

Key words: Oryza sativa L., chisel plow, harrow, no-tillage, sprinkler-irrigation, compaction.

\section{INTRODUÇÃO}

O arroz constitui fonte importante de calorias e de proteínas na dieta alimentar do povo brasileiro. Áreas irrigadas requerem cultivo intensivo para otimizar o uso da terra e do sistema de irrigação. É importante enfatizar que o manejo incorreto do solo causa sérios danos em suas propriedades físicas, o que pode limitar o desenvolvimento radicular e armazenamento de água, comprometendo o crescimento e a produtividade das plantas. Por isso, o enfoque dado aos sistemas de manejo do solo e da água tem aumentado nos últimos anos, por meio dos quais busca-se maximizar o uso do solo e da água, para se alcançar a sustentabilidade do sistema agrícola. Não se deve esperar que solos sob cultivo mantenham as suas características físicas originais, mas deve-se procurar manejá-los de modo que altere o mínimo possível estas características; especialmente as que afetam a infiltração e retenção de água, como a porosidade e a agregação, para manter a sustentabilidade do sistema.

A região dos cerrados ocupa $24 \%$ da área do território brasileiro, tornando-se importante na produção de grãos com a expansão da fronteira agrícola. De modo geral, os sistemas de preparo nesta região se caracterizam pelo alto grau de revolvimento do solo, por meio do uso da grade aradora e arado de discos, que acarretam impactos negativos nas propriedades físicas do solo, comprometendo a sustentabilidade ambiental (CORRECHEL et al., 1999).

As mobilizações intensivas do solo, no sistema convencional, sob condições inadequadas de umidade e de cobertura vegetal, modificam adversamente a estrutura do solo, afetando basicamente as relações entre as fases sólida, liquida e gasosa. Desta forma, transformam a camada arável em superficial pulverizada e a subsuperficial compactada. De acordo com Pedroso e Corsini (1983), no preparo convencional do solo as operações são realizadas continuamente em uma mesma profundidade podendo ocasionar em alguns tipos de solo uma camada compactada resultante da pressão do arado como também da grade sobre o solo, conhecidas como "pé-de-arado" e "pé-de-grade". O sistema semeadura direta é um sistema de produção agrícola em que a semeadura da cultura é feita sem preparo do solo, mantendo os restos culturais dos cultivos anteriores na superfície, sendo um sistema de manejo eficaz na proteção da superfície do solo contra agentes erosivos. Todavia, como não há revolvimento do solo, pode ocorrer a formação de camadas compactadas na distribuição das pressões exercidas na superfície do solo pelas máquinas e implementos (Denardin e KochHann, 1997). Essa compactação superficial do solo é caracterizada pelo aumento da densidade do solo e redução de sua porosidade total (Tavares Filho, 1995; Tavares Filho e Tessier, 1998), a qual poderá restringir o desenvolvimento radicular das culturas.

De acordo com Guimarães e Moreira (2001), o crescimento da parte aérea do arroz de terras altas é menor com o aumento da densidade do solo, e a compactação na camada superficial diminui a quantidade de raízes presentes nesta camada e na camada inferior não compactada.

A permeabilidade do solo depende, dentre outros fatores, da quantidade, continuidade e do tamanho de poros, sendo a compactação e a descontinuidade dos poros responsáveis pela redução significativa da permeabilidade do solo à água. $\mathrm{O}$ conhecimento da velocidade de infiltração da água no solo e da condutividade hidráulica é fundamental para a solução de problemas relativos às áreas de irrigação, drenagem, conservação da água e do solo e controle do deflúvio superficial, sendo de grande importância para o manejo do solo e da água o entendimento do processo de infiltração e de suas relações com as propriedades do solo (Souza e Alves, 2003). O trabalho teve como objetivo avaliar o efeito do manejo do solo e da água nas propriedades físicas de um Latossolo Vermelho cultivado com arroz de terras altas irrigado por aspersão no município de Selvíria (MS). 


\section{MATERIAL E MÉTODOS}

A pesquisa foi desenvolvida no ano agrícola de 2003/2004, em Selvíria (MS). O solo do local é do tipo Latossolo Vermelho Distrófico, argiloso, A moderado, hipodistrófico, álico, caulinítico, férrico, compactado, muito profundo, moderadamente ácido (Demattê, 1980; Embrapa, 1999). O teor de argila, areia e silte do solo é, respectivamente, 456,451 e $93 \mathrm{~g} \mathrm{~kg}^{-1}$ na profundidade de 0 a $0,1 \mathrm{~m} ; 422,480$ e $98 \mathrm{~g} \mathrm{~kg}^{-1}$ na profundidade de 0,1 a $0,2 \mathrm{~m}$ e 474,439 e $87 \mathrm{~g} \mathrm{~kg}^{-1}$, respectivamente, na profundidade de 0,2 a $0,4 \mathrm{~m}$. A precipitação pluvial média anual é de $1.370 \mathrm{~mm}$, a temperatura média anual é de $23,5{ }^{\circ} \mathrm{C}$ e a umidade relativa do ar entre $70 \%$ e $80 \%$ (média anual).

O delineamento experimental utilizado foi em blocos casualizados em esquema fatorial $3 \times 3$, constituídos pela combinação de três manejos do solo (escarificador + grade niveladora, grade pesada + grade niveladora e semeadura direta), três manejos da água (sem irrigação, irrigação nas fases reprodutiva e de maturação, e irrigação em todas as fases), com quatro repetições. $\mathrm{O}$ experimento foi instalado em área em que havia sido semeado o milheto no cultivo anterior para produção de cobertura morta (com produção média de matéria seca de $4.400 \mathrm{~kg} \mathrm{ha}^{-1}$ ), sendo dessecada com ghyphosate ( $1.560 \mathrm{~g} \mathrm{ha}^{-1}$ do i.a.). Os tratamentos com semeadura direta foram instalados em local onde o sistema foi implantado no ano agrícola 1996/1997.

O fornecimento de água foi realizado com um sistema fixo de irrigação convencional por aspersão com precipitação média de $3,3 \mathrm{~mm}^{\text {hora }}{ }^{-1}$ nos aspersores. A precipitação pluvial foi avaliada em um pluviômetro Ville de Paris instalado na área experimental. No manejo de água foram utilizados, dependendo do tratamento, até três coeficientes de cultura (Kc), distribuídos em quatro períodos compreendidos entre a emergência e a colheita. Para a fase vegetativa foi utilizado o valor de 0,4 ; para a fase reprodutiva dois coeficientes de cultura $(\mathrm{Kc})$, o inicial de 0,70 e o final de 1,00 e para a fase de maturação estes valores foram invertidos, ou seja, o inicial de 1,00 e o final de 0,70. Os coeficientes de cultura foram adotados seguindo metodologia de ARF et al. (2005). As parcelas foram constituídas por seis linhas de 6,0 m de comprimento espaçadas de $0,35 \mathrm{~m}$ entre si. A área útil foi constituída pelas quatro linhas centrais, desprezando-se $0,50 \mathrm{~m}$ em ambas as extremidades de cada linha.

A semeadura foi realizada em 24 de novembro de 2003, utilizando a cultivar BRS - Talento, com 120 plantas $\mathrm{m}^{-2}$. A adubação química básica nos sulcos de semeadura foi constituída da aplicação de $200 \mathrm{~kg}$ $\mathrm{ha}^{-1}$ da formulação 8-28-16. Em 5/1/2004 foi realizada a adubação nitrogenada em cobertura utilizando-se $75 \mathrm{~kg} \mathrm{ha}^{-1}$ de nitrogênio utilizando como fonte a uréia.

A coleta das amostras de solo para as avaliações foi realizada na fase de florescimento da cultura $(20 / 2 / 2004)$. Foram coletadas amostras indeformadas com anéis volumétricos (capacidade de $10^{-4} \mathrm{~m}^{3}$ ) para as análises das propriedades físicas do solo, nas camadas de 0 a $0,10 \mathrm{~m}, 0,10$ a $0,20 \mathrm{~m}$ e 0,20 a $0,40 \mathrm{~m}$. As propriedades físicas do solo analisadas foram: densidade do solo e porosidade total, pelo método do anel volumétrico; microporosidade pelo método da mesa de tensão com coluna de água de 0,60 $\mathrm{m}$ e a macroporosidade foi calculada por diferença entre a porosidade total e a microporosidade. Todas as avaliações foram realizadas de acordo com a EMBRAPA (1997). A resistência do solo à penetração foi medida com um penetrógrafo (Penetrographer $\mathrm{PAT}^{\mathrm{SC}-60}$ ) nas camadas de solo de 0,00 a $0,10 \mathrm{~m} ; 0,10$ a $0,20 \mathrm{~m}$ e 0,20 a $0,40 \mathrm{~m}$. Também foi determinada a umidade do solo no momento da avaliação da resistência, nas mesmas camadas de solo, de acordo com metodologia da Embrapa (1997). A condutividade hidráulica do solo saturado e a infiltração de água foram medidas no campo utilizando-se um permeâmetro de Guelph, em três profundidades $(0,10 ; 0,20$ e $0,40 \mathrm{~m})$ empregando-se duas cargas hidráulicas, de 0,03 e 0,06 m (REYNOLDS e ELRICK, 1987).

Todos os efeitos dos tratamentos foram avaliados por meio da análise de variância utilizando o programa SANEST - Sistema de Análise Estatística para microcomputadores (ZONTA e MACHADO, 1986).

\section{RESULTADOS E DISCUSSÃO}

O preparo com escarificador resultou em maior macroporosidade na camada de solo de 0,00-0,10 e 0,10-0,20 m (Tabela 1). Normalmente, nos sistemas com revolvimento (grade pesada), há persistência dos efeitos da mobilização do solo que resultam em fraturamento dos agregados e no desenvolvimento de poros, proporcionando aumento na macroporosidade (Klein et al., 1998; Souza e Alves, 2003). Porém, os resultados desse trabalho não refletem este comportamento, pois no sistema com escarificação, a macroporosidade foi maior em relação à grade pesada, evidenciando que este sistema de preparo do solo contribuiu para a melhoria da qualidade de sua estrutura. Deve-se ressaltar também que na camada de $0,10-0,20 \mathrm{~m}$ a grade pesada proporcionou macroporosidade de $0,09 \mathrm{~m}^{3} \mathrm{~m}^{-3}$, e o limite crítico para o bom desenvolvimento do sistema radicular é 0,10 $\mathrm{m}^{3} \mathrm{~m}^{-3}$ (Vomocil e Flocker, 1966; GreENLAND, 1981). 
Tabela 1. Valores médios de macroporosidade e microporosidade em função do manejo do solo e da água em diferentes camadas. Selvíria (MS), 2003/2004

\begin{tabular}{|c|c|c|c|c|c|c|}
\hline \multirow{2}{*}{ Tratamentos } & \multicolumn{2}{|c|}{$0,00-0,10 \mathrm{~m}$} & \multicolumn{2}{|c|}{$0,10-0,20 \mathrm{~m}$} & \multicolumn{2}{|c|}{$0,20-0,40 \mathrm{~m}$} \\
\hline & Macro $\left({ }^{1}\right)$ & Micro $\left({ }^{2}\right)$ & Macro & Micro & Macro & Micro \\
\hline & & & 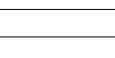 & & & \\
\hline & & & Mar & solo & & \\
\hline Escarificador + G.N. & $0,19 a$ & 0,28 & $0,18 \mathrm{a}$ & $0,27 b$ & 0,13 & $0,33 a$ \\
\hline Grade pesada + G.N. & $0,13 b$ & 0,28 & $0,09 b$ & $0,31 \mathrm{a}$ & 0,15 & $0,32 \mathrm{a}$ \\
\hline \multirow[t]{2}{*}{ Semeadura direta + G.N. } & $0,10 b$ & 0,29 & $0,12 b$ & $0,29 \mathrm{ab}$ & 0,13 & $0,30 \mathrm{~b}$ \\
\hline & \multicolumn{6}{|c|}{ Manejo da água } \\
\hline Todas as fases & 0,14 & 0,29 & 0,13 & 0,29 & 0,13 & 0,32 \\
\hline Reprodutiva e maturação & 0,14 & 0,28 & 0,13 & 0,30 & 0,14 & 0,32 \\
\hline Sem irrigação & 0,13 & 0,28 & 0,12 & 0,29 & 0,16 & 0,32 \\
\hline CV (\%) & 34,1 & 8,6 & 29,3 & 7,9 & 17,9 & 4,8 \\
\hline
\end{tabular}

Médias seguidas de letras iguais na coluna, dentro de cada fator, não diferem estatisticamente entre si, pelo teste de Tukey a 5 \% de probabilidade. $\left({ }^{1}\right)$ Macroporosidade. $\left({ }^{2}\right)$ Microporosidade; GN = Grade niveladora.

Este fato pode ser atribuído à presença de "péde-grade" (camada compactada) causada pelo implemento de preparo do solo utilizado nesse sistema juntamente também pela ação da grade niveladora. Na camada de 0,20 a 0,40 m não ocorreu influência do manejo do solo em relação à macroporosidade do solo. Outro dado importante verificado na tabela 1 é que a macroporosidade na semeadura direta aumentou nas camadas inferiores, visto que esse sistema propicia a compactação do solo mais superficial, decorrente do tráfego de máquinas, muitas vezes com solo em condições de umidade acima de seu ponto de friabilidade. O manejo da água não interferiu na macroporosidade em nenhuma das profundidades analisadas.

Quanto ao manejo de água verificou-se que não houve diferença significativa entre os tratamentos (irrigado em todas as fases, irrigado nas fases reprodutivas e de maturação e sem irrigação), para todas as propriedades físicas do solo estudadas. Provavelmente, a quantidade de matéria seca produzida pela cultura do arroz e que retornou ao solo, até o momento, não causou efeito quanto às mudanças na sua estrutura (KAMIMURA, 2005). Essas mudanças influenciariam diretamente todas as propriedades físicas analisadas nessa pesquisa.

$\mathrm{Na}$ camada de 0,10 a $0,20 \mathrm{~m}$, a microporosidade foi maior no preparo com grade pesada quando comparada ao escarificador, e a semeadura direta não diferiu dos demais tratamentos (Tabela 1). Esse fato ocorre, provavelmente, devido às operações de preparo do solo nesse sistema, as quais ocasionam diferença decorrente da pulverização na camada superficial. CRUz et al. (2003) verificaram que nos sistemas convencionais há maior microporosidade na camada de 0,10 a $0,20 \mathrm{~m}$ provavelmente como resultado das operações de preparo do solo (camada compactada). Na camada de 0,20 a $0,40 \mathrm{~m}$, no preparo com escarificador e grade pesada ocorreram maiores valores de microporosidade quando comparado à semeadura direta. A microporosidade não foi influenciada pelo manejo da água.

Nas camadas de 0,00 a 0,10 m e de 0,10 a 0,20 $\mathrm{m}$, a escarificação condicionou os maiores valores de porosidade total quando comparada à semeadura direta e grade pesada. Já na camada de 0,20 a $0,40 \mathrm{~m}$, durante o preparo com grade pesada houve maior porosidade total quando comparado à semeadura direta, porém não diferindo do escarificador. TORMENA et al. (2002) e CRUz et al. (2003) verificaram que o preparo convencional do solo promoveu aumento na porosidade do mesmo, quando comparada ao sistema semeadura direta. O manejo da água, porém, não teve efeito sobre a porosidade total.

Quando analisada a densidade do solo (Tabela 2) verificou-se diferença significativa apenas para o manejo do solo na camada de 0,00 a 0,10 e 0,10 a 0,20 m. A semeadura direta e o preparo com grade pesada proporcionaram maiores valores se comparados com o escarificador, resultados semelhantes foram obtidos por De MARIA et al. (1999). Os maiores valores de densidade do solo na camada de 0,00 a $0,10 \mathrm{~m}$ na semeadura direta podem ser decorrentes do tráfego de máquinas na área, o qual leva a uma acomodação da camada superficial do solo. CRUz et al. (2003) também observaram maior densidade do solo na semeadura direta. Na densidade do solo não houve efeito do manejo da água. 
Tabela 2. Valores médios de porosidade total e densidade do solo em função do manejo do solo e da água em diferentes camadas. Selvíria (MS), 2003/2004

\begin{tabular}{|c|c|c|c|c|c|c|}
\hline \multirow{2}{*}{ Tratamentos } & \multicolumn{2}{|c|}{$0,00-0,10 \mathrm{~m}$} & \multicolumn{2}{|c|}{$0,10-0,20 \mathrm{~m}$} & \multicolumn{2}{|c|}{$0,20-0,40 \mathrm{~m}$} \\
\hline & P.Total $\left({ }^{1}\right)$ & Dens. $\left({ }^{2}\right)$ & P.Total & Dens. & P.Total & Dens. \\
\hline & $\mathrm{m}^{3} \mathrm{~m}^{-3}$ & $\mathrm{~kg} \mathrm{dm} \mathrm{m}^{-3}$ & $\mathrm{~m}^{3} \mathrm{~m}^{-3}$ & $\mathrm{~kg} \mathrm{dm} \mathrm{m}^{-3}$ & $\mathrm{~m}^{3} \mathrm{~m}^{-3}$ & $\mathrm{~kg} \mathrm{dm}{ }^{-3}$ \\
\hline & & & Manejo do & & & \\
\hline Escarificador + G.N. & $0,47 a$ & $1,34 b$ & $0,45 a$ & $1,41 b$ & $0,46 a b$ & 1,40 \\
\hline Grade pesada + G.N. & $0,42 b$ & $1,49 \mathrm{a}$ & $0,40 \mathrm{~b}$ & $1,56 a$ & $0,47 a$ & 1,35 \\
\hline \multirow[t]{2}{*}{ Semeadura direta + G.N. } & $0,39 b$ & $1,56 a$ & $0,42 b$ & $1,50 \mathrm{a}$ & $0,44 b$ & 1,42 \\
\hline & \multicolumn{4}{|c|}{ Manejo da água } & & \\
\hline Todas as fases & 0,43 & 1,49 & 0,42 & 1,49 & 0,46 & 1,38 \\
\hline Reprodutiva e maturação & 0,42 & 1,49 & 0,43 & 1,73 & 0,46 & 1,38 \\
\hline Sem irrigação & 0,44 & 1,44 & 0,42 & 1,50 & 0,45 & 1,41 \\
\hline CV (\%) & 8,3 & 5,7 & 7,9 & 5,3 & 5,0 & 4,9 \\
\hline
\end{tabular}

Médias seguidas de letras iguais na coluna, dentro de cada fator, não diferem estatisticamente entre si, pelo teste de Tukey a 5 \% de probabilidade. $\left({ }^{1}\right)$ Porosidade total. $\left({ }^{2}\right)$ Densidade do solo. GN = Grade niveladora.

Na camada de 0,00 a 0,10 m, a resistência à penetração (Tabela 3) foi maior no preparo com grade pesada, se comparada ao preparo com escarificador, porém não diferindo da semeadura direta. Já na camada de 0,10 a $0,20 \mathrm{~m}$ os manejos do solo com grade pesada e semeadura direta não diferiram estatisticamente entre si, mas observaram-se maiores valores de resistência à penetração, se comparado com escarificador. SILVA et al. (2000) verificaram maiores valores de resistência à penetração no cultivo convencional (1 aração e 2 gradagens), sendo críticos na camada de 0,05 a $0,20 \mathrm{~m}$, com valores superiores a $2 \mathrm{MPa}$ no cultivo convencional e na semeadura direta. Na camada de 0,20 a $0,40 \mathrm{~m}$, na semeadura direta houve maior resistência à penetração, comparada ao preparo do solo com escarificador, entretanto não diferiu do preparo com grade pesada, confirmando resultados obtidos por CENTURION e Demattê (1992). No manejo do solo sob semeadura direta há tendência de compactação superficial $(0,00$ $0,20 \mathrm{~m}$ ) e queda nos valores em subsuperfície, indicando melhoria na qualidade física do solo em profundidade, decorrentes da ação da meso e macrofauna e de raízes, que atuam na formação de canais, confirmando resultados observados por CosTA et al. (2003).

Tabela 3. Valores médios de resistência à penetração do solo e umidade do solo em função do manejo do solo e da água em diferentes camadas. Selvíria (MS), 2003/2004

\begin{tabular}{|c|c|c|c|c|c|c|}
\hline \multirow{2}{*}{ Tratamentos } & \multicolumn{2}{|c|}{$0,00-0,10 \mathrm{~m}$} & \multicolumn{2}{|c|}{$0,10-0,20 \mathrm{~m}$} & \multicolumn{2}{|c|}{$0,20-0,40 \mathrm{~m}$} \\
\hline & R.Penet. $\left({ }^{1}\right)$ & Umid. $\left({ }^{2}\right)$ & R.Penet. & Umid. & R.Penet. & Umid. \\
\hline & $\mathrm{MPa}$ & $\mathrm{kg} \mathrm{kg}^{-1}$ & $\mathrm{MPa}$ & $\mathrm{kg} \mathrm{kg}^{-1}$ & $\mathrm{MPa}$ & $\mathrm{kg} \mathrm{kg}^{-1}$ \\
\hline & \multicolumn{6}{|c|}{ Manejo do solo } \\
\hline Escarificador + G.N. & $1,31 \mathrm{~b}$ & 0,14 & $1,43 b$ & 0,16 & $1,58 \mathrm{~b}$ & 0,18 \\
\hline Grade pesada + G.N. & $2,46 a$ & 0,13 & $2,10 \mathrm{a}$ & 0,17 & $1,60 \mathrm{ab}$ & 0,19 \\
\hline \multirow[t]{2}{*}{ Semeadura direta + G.N. } & $2,06 a b$ & 0,15 & $2,01 \mathrm{a}$ & 0,16 & $1,97 \mathrm{a}$ & 0,18 \\
\hline & \multicolumn{6}{|c|}{ Manejo da água } \\
\hline Todas as fases & 1,53 & 0,14 & 1,87 & 0,16 & 1,87 & 0,19 \\
\hline Reprodutiva e maturação & 2,20 & 0,14 & 1,80 & 0,16 & 1,67 & 0,19 \\
\hline Sem irrigação & 2,09 & 0,13 & 1,87 & 0,16 & 1,65 & 0.18 \\
\hline $\mathrm{CV}(\%)$ & 44,3 & 13,3 & 29,7 & 6,5 & 21,5 & 7,5 \\
\hline
\end{tabular}

Médias seguidas de letras iguais na coluna, dentro de cada fator, não diferem estatisticamente entre si, pelo teste de Tukey a $5 \%$ de probabilidade. $\left({ }^{1}\right)$ Resistência à penetração. $\left({ }^{2}\right)$ Umidade do solo. GN= Grade niveladora. 
Comparando-se os valores de resistência à penetração do solo obtidos nos tratamentos estudados, com os resultados publicados por CARAnache (1990), na tabela 4 (solo com umidade na capacidade de campo), verificou-se que em todas as camadas estudadas os valores estavam na classe baixa, ou seja, com pouca limitação ao crescimento das raízes. Entretanto, deve-se ressaltar que a cultura do arroz é extremamente sensível à compactação superficial. A resistência à penetração do solo não foi influenciada pelos diferentes manejos da água.

Tabela 4. Limites de classes de resistência de solos à penetração e graus de limitação ao crescimento das raízes. Umidade do solo na capacidade de campo

\begin{tabular}{lcc}
\hline Classes & Limites MPa & Limitações ao crescimento das plantas raízes \\
\hline Muito baixa & $<1,1$ & Sem limitação \\
Baixa & $1,1-2,5$ & Pouca limitação \\
Média & $2,6-5,0$ & Algumas limitações \\
Alta & $5,1-10,0$ & Sérias limitações \\
Muito alta & $10,1-15,0$ & Raízes praticamente não crescem \\
Extremamente alta & $>15,0$ & Raízes não crescem \\
\hline
\end{tabular}

Fonte: CARANACHE (1990).

A umidade do solo (Tabela 3) não foi influenciada pelos manejos do solo e da água nas três camadas de solo estudadas. Como não houve diferença na umidade do solo, provavelmente não influenciou os resultados da resistência à penetração.

A condutividade hidráulica do solo saturado (Tabela 5) foi influenciada pelo manejo do solo na profundidade de 0,00 a $0,10 \mathrm{~m}$, tendo a grade pesada o maior valor em relação à semeadura direta, mas não diferindo do manejo do solo com escarificador. Esse maior valor no preparo convencional é função da ação do implemento de preparo do solo (mobilização) Resultados semelhantes foram constatados por CORRÊA (1985), Pelegrini et al. (1990) e Pierce et al. (1992), que verificaram maior condutividade hidráulica no preparo convencional do solo na camada superficial. Para as profundidades de 0,10 a $0,20 \mathrm{~m}$ e 0,20 a 0,40 $\mathrm{m}$ mesmo não havendo diferenças estatísticas, podese observar que com a grade pesada ocorreu menor condutividade hidráulica do solo saturado.

A condutividade hidráulica do solo saturado reduziu-se nas profundidades de 0,20 e $0,40 \mathrm{~m}$, provavelmente devido à redução da porosidade, também expressa pelo aumento na densidade do solo, exceto na semeadura direta, em que houve aumento, em decorrência da maior continuidade dos poros por não haver revolvimento do solo pelo preparo. Esse fato facilitou a movimentação da água no solo.

Tabela 5. Valores médios de condutividade hidráulica do solo saturado $\left(\mathrm{mm} \mathrm{h}^{-1}\right)$ e taxa de infiltração de água (mm $\mathrm{h}^{-}$

${ }^{1}$ ) em função do manejo do solo e da água em diferentes camadas. Selvíria (MS), 2003/2004

\begin{tabular}{|c|c|c|c|c|c|c|}
\hline \multirow{2}{*}{ Tratamentos } & \multicolumn{2}{|c|}{ 0,00-0,10 m } & \multicolumn{2}{|c|}{$0,10-0,20 \mathrm{~m}$} & \multicolumn{2}{|c|}{$0,20-0,40 \mathrm{~m}$} \\
\hline & Kfs $\left({ }^{1}\right)$ & Inf. $\left({ }^{2}\right)$ & Kfs & Inf. & Kfs & Inf. \\
\hline & \multicolumn{6}{|c|}{$\mathrm{mm} \mathrm{h}^{-1}$} \\
\hline & \multicolumn{6}{|c|}{ Manejo do solo } \\
\hline Escarificador + G.N. & $16,90 \mathrm{ab}$ & $10,38 \mathrm{a}$ & 10,77 & 8,56 & 11,17 & 8,56 \\
\hline Grade pesada + G.N. & $27,49 a$ & $16,63 a$ & 6,49 & 5,20 & 15,62 & 12,98 \\
\hline \multirow[t]{2}{*}{ Semeadura direta + G.N. } & $4,58 b$ & $3,76 b$ & 12,32 & 8,91 & 10,45 & 10,23 \\
\hline & \multicolumn{6}{|c|}{ Manejo da água } \\
\hline Todas as fases & 25,07 & 11,83 & 11,27 & 9,45 & 10,77 & 11,67 \\
\hline Reprodutiva e maturação & 13,72 & 10,65 & 8,47 & 6,88 & 13,63 & 9,81 \\
\hline Sem irrigação & 10,19 & 8,29 & 9,8 & 6,34 & 12,85 & 10,29 \\
\hline CV (\%) & 85,0 & 62,5 & 88,2 & 80,3 & 78,4 & 67,6 \\
\hline
\end{tabular}

Médias seguidas de letras iguais na coluna, dentro de cada fator, não diferem estatisticamente entre si, pelo teste de Tukey a 5 \% de probabilidade. $\left({ }^{1}\right)$ Condutividade hidráulica do solo saturado. $\left({ }^{2}\right)$ Infiltração de água. GN = Grade niveladora. 
De acordo com SouzA et al. (2003), no cultivo mínimo a condutividade hidráulica do solo saturado diminui em profundidade $(0,00$ a 0,$10 ; 0,10$ a 0,20 e 0,20 a $0,40 \mathrm{~m}$ ). Entretanto, nos sistemas com plantio direto e preparo convencional do solo, não houve diferenças entre as profundidades em relação a essa condutividade hidráulica. Neste estudo, foram avaliados altos valores de coeficientes de variação para a condutividade hidráulica do solo saturado. Costa et al. (2003), e Souza e Alves (2003) também observaram valores elevados de coeficiente de variação para a condutividade hidráulica do solo saturado. De acordo com SARVASI (1994), pode-se atribuir o efeito local aos altos coeficientes de variação proporcionando, desta forma, variações notáveis no comportamento dos sistemas estudados.

Em conformidade com a condutividade hidráulica do solo saturado, verificou-se o mesmo comportamento para a infiltração de água no solo (Tabela 5). Pelos dados obtidos, verificou-se que para os tratamentos com maior desestruturação do solo devido à mobilização pelo implemento (escarificador e grade pesada), houve elevada taxa de infiltração na camada de solo mobilizada e queda nas camadas inferiores. Entretanto, na semeadura direta houve aumento da infiltração nas profundidades inferiores e diminuição na densidade do solo e resistência do solo à penetração, em decorrência do aumento na macroporosidade e porosidade total.

A baixa taxa de infiltração na profundidade de 0,00 a $0,10 \mathrm{~m}$, neste sistema de manejo, decorre da compactação superficial pelo trânsito de máquinas na área. Segundo Souza e Alves (2003), as modificações na distribuição das partículas do solo que provocam diminuição no tamanho dos poros, especialmente daqueles de tamanho maior (macroporos), impelem também redução na área da seção transversal para o fluxo de água, que juntamente com percursos mais tortuosos para movimento de fluido afetam o comportamento hidrodinâmico, de acordo com os manejos do solo utilizados. Mesmo não havendo diferença estatística, na profundidade de 0,10 a $0,20 \mathrm{~m}$, verificou-se que com a grade pesada houve menor infiltração de água devido à presença de camada compactada ("pé-de-grade"), pois essa infiltração reflete as condições físicas do solo, como estrutura, porosidade e camada compactada.

O sistema de preparo do solo com escarificador + grade niveladora proporcionou ao solo maior macroporosidade e porosidade total, e menor densidade do solo e resistência à penetração, além de elevada condutividade hidráulica e infiltração de água na camada arável de 0,00 a $0,20 \mathrm{~m}$. Portanto, este sistema proporcionou as melhores condições físicas do solo para o cultivo do arroz de terras altas, quando comparado aos outros sistemas de preparo do solo utilizados. Essa cultura é muito sensível à compactação, o que muitas vezes impede seu desenvolvimento, afetando sua produtividade (Guimarães e Moreira, 2001).

Como pode ser observado nos dados obtidos, a semeadura direta foi o manejo do solo que proporcionou menor macroporosidade e porosidade total, além de maior resistência à penetração e densidade do solo nos primeiros $0,10 \mathrm{~m}$ do solo, o que muitas vezes interfere negativamente no desenvolvimento do sistema radicular do arroz, levando à menor produtividade de grãos.

A alteração desses atributos do solo é devido ao processo de compressão causado por tráfego de máquinas nesse sistema (plantio, tratos culturais e colheita). Resultados semelhantes foram verificados por Centurion e Demattê (1992). Pode-se ainda verificar que no preparo do solo com grade pesada + grade niveladora, houve a formação de camada compactada na camada de 0,10-0,20 m, ou seja "péde-grade", resultados também constatados por Pedroso e Corsini (1983), e Fornasieri Filho e ForNASIERI (1993).

O preparo com grade pesada + grade niveladora proporcionou menor macroprosidade e porosidade total, maior densidade do solo e resistência à penetração, além de menor condutividade hidráulica do solo saturado e infiltração de água nessa camada do solo, em decorrência, provavelmente, da ação do implemento de preparo do solo utilizado.

\section{CONCLUSÕES}

1. As propriedades físicas do solo foram influenciadas pelo manejo do solo, mas não afetadas pelo manejo da água.

2. O sistema de preparo do solo com escarificador + grade niveladora foi o que resultou em melhores condições físicas para o desenvolvimento da cultura do arroz, quando comparado aos outros sistemas utilizados no trabalho.

\section{AGRADECIMENTOS}

À Fundação de Amparo a Pesquisa do Estado de São Paulo (FAPESP), pelo financiamento e a concessão da bolsa para realização do projeto de pesquisa. 


\section{REFERÊNCIAS}

ARF, O.; BASTOS, J.C.H.A.G.; SILVA, M.G.; SÁ, M.E.; RODRIGUES, R.A.F.; BUZETT, S. Manejo do solo e época de aplicação de nitrogênio na produção de arroz de terras altas. Acta Scientiarum Agronomy, v.27, p.215-223, 2005.

CARANACHE, A. PENETR - A generalized semi-empirical model estimating soil resistance to penetration. Soil Tillage Research, v.16, p.51-70, 1990.

CENTURION, J.F.; DEMATTÊ,J. L. I. Sistemas de preparo de solos de cerrado: Efeitos nas propriedades físicas e na cultura do milho. Pesquisa Agropecuária Brasileira, v.27, p.315-324, 1992.

CORRÊA, J.C. Característica física de um Latossolo Amarelo muito argiloso. Pesquisa Agropecuária Brasileira, v.20, p.13811387, 1985.

CORRECHEL, V.;SILVA, A.P.; TORMENA, C. A. Influencia da posição relativa da linha de cultivo sobre a densidade do solo em dois sistemas de manejo do solo. Revista Brasileira de Ciência do Solo, v.23, p.165-172, 1999.

COSTA, F.S; ALBUQUERQUE, J. A.; BAYER, C.; FONTOURA, S. M. V.; WOBETO, C. Propriedades físicas de um latossolo Bruno afetadas pelos sistemas plantio direto e preparo convencional. Revista Brasileira de Ciência do Solo, v.27, p.527-535, 2003.

CRUZ, A.C. R.; PAULETTO, E.A.; FLORES, C.A.; SILVA, J.B. Atributos físicos e carbono orgânico de um argissolo vermelho sob sistemas de manejo. Revista Brasileira de Ciência do Solo, v.27, p.1105-1112, 2003.

DE MARIA, I.C; CASTRO; O. M.; SOUZA DIAS, H. Atributos físicos do solo e crescimento radicular de soja em Latossolo roxo sob diferentes métodos de preparo do solo. Revista Brasileira de Ciência do Solo, v.23, n.3, p.703-709, 1999.

DEMATTÊ, J. L. I. Levantamento detalhado dos solos do "Campus experimental de Ilha Solteira". Piracicaba: Departamento de Solos, Geologia e Fertilidade, ESALQ/USP, 1980. p.11-31.

DENARDIN, J.E.; KOCHHANN, R.A. Pesquisa de desenvolvimento em sistema plantio direto no Rio Grande do Sul. In: CONGRESSO BRASILEIRO DE CIÊNCIA DO SOLO, 26., 1997, Rio de Janeiro. Palestras.... Rio de Janeiro, 1997. (CD-ROM).

EMPRESA BRASILEIRA DE PESQUISA AGROPECUÁRIA Embrapa/CNPSo. Sistema Brasileiro de Classificação dos solos. Rio de janeiro: Embrapa/CNPSo, 1999, 412 p.

EMPRESA BRASILEIRA DE PESQUISA AGROPECUÁRIA. Manual de métodos de análise de solo. 2.ed. Rio de Janeiro: EMBRAPA/CNPSO, 1997. 212p.

FORNASIERI FILHO, D.; FORNASIERI, J.L. Manual da cultura do arroz. Jaboticabal: FUNEP, 1993.221p.
GREENLAND, D.J. Soil Management and soil degradation. Journal of Soil Science, v.31, p.301-322, 1981.

GUIMARAES, C.M.; MOREIRA, J.A.A. Compactação do solo na cultura do arroz de terras altas. Pesquisa Agropecuária Brasileira, Brasília, v. 36, n.4, p.703-707, 2001.

KAMIMURA, K.M. Manejo do solo e da água nas propriedades físicas, químicas e térmicas do solo e produtividade do arroz de terras altas. 2005. 127p. Trabalho de graduação-FE/UNESP, Ilha Solteira.

KLEIN, V.A.; LIBARDI, P.L.; SILVA, A.P.da Resistência mecânica do solo à penetração sob diferentes condições de densidade e teor de água. Engenharia Agrícola, v.18, n.2, p.4554, 1998.

PELEGRINI, F.; MORENO, F.; MARTIN-ARANHA, J.; CAMPS, $M$. The influence of tillage methods is soil physical properties and water balance for a typical crop rotation SW Spain. Soil Tillage Research, v.16, p.345-358, 1990.

PEDROSO, P.A.C.; CORSINI, P. C. Manejo físico do solo. In: FERREIRA, M.E.; YAMADA, T.; MALAVOLTA, E. Cultura do arroz de sequeiro: fatores afetando a produtividade. Piracicaba: Associação Brasileira para a Pesquisa da Potassa e do Fosfato, 1983. p.225-238.

PIERCE, f.J.; FORTIN, M.C.; STATON, M.J. Immediate and residual effects of zone-tillage in rotation with no-tillage on soil physical properties and corn performace. Soil Tillage Research. v.24, n.1, p.149-165, 1992.

REYNOLDS, W.D.; ELRICK, D.E. Laboratory and numerical assement of the guelph permeater method. Soil Science, v.144, p.282-299, 1987.

SARVASI, F.O.C. Dinâmica da água, erosão hídrica e produtividade das culturas em função do preparo do solo. 1994. 161p. Dissertação Mestrado - ESALQ/USP. Piracicaba.

SILVA, M.L.N.; CURI, N.; BLANCANEAUX, P. Sistemas de manejo e qualidade estrutural de latossolo roxo. Pesquisa Agropecuária Brasileira, v.35, p.2485-2492, 2000.

SOUZA, Z.M.; ALVES, M.C. Movimento de água e resistência a penetração em um latossolo vermelho distrófico de cerrado, sob diferentes usos e manejos. Revista Brasileira de Engenharia Agrícola e Ambiental, v.7, p. 18-23, 2003.

SOUZA, Z.M.; ALVES, M.C. Propriedades físicas e teor de matéria orgânica em um Latossolo Vermelho de cerrado sob diferentes usos e manejos. Acta Scientiarum Agronomy, v.25, n.1, p.27-34, 2003.

TAVARES FILHO, J. Organisation et comportement des latosols du Paraná (Brésil). Influence de leur mise em valeur. 1995. 229p. Tese (Doutorado) - Université de Nancy I, Nancy.

TAVARES FILHO, J.; TESSIER, D. Influence dês pratiques culturales sur lê comportement et lês propriétes de sols du Paraná (Brésil). Étude Gestion Sols, v.5, p.61-71, 1998. 
TORMENA,C. A.; BARBOSA, M. C.; COSTA, A. C. S; GONÇALVES, C. A. Densidade, porosidade e resistência à penetração em latossolo cultivado sob diferentes sistemas de preparo do solo. Scientia Agrícola, v.59, n.4, 2002.

VOMOCIL, J.A.; FLOCKER, W.J. Effects of soil compaction on storage and movement of soil and water. Transaction the American Society of Agricultural Engineers, v.4, p.242-246, 1966.

ZONTA, E.P.; MACHADO, A.A. Sistema de Análise Estatística para microcomputadores- SANEST. Pelotas: UFPel, Instituto de Física e Matemática, 1986. 150p. 